\section{Acridologists' vademecum}

Grasshoppers and Locusts. Vo1. 2. By Boris Uvarov. Pp. 613. (Centre for Overseas Pest Research: London, 1977.) $£ 16$.

ON retirement, Sir Boris Uvarov undertook the preparation of "a synthesis of present-day knowledge of the theory and practice of acridology", and this publication sees the eventual fulfilment of that task after his death in 1970. The first volume covering anatomy, physiology, development, phase polymorphism and an introduction to taxonomy came out in 1966 (Cambridge University Press). This second, posthumous volume covers behaviour (10 chapters) and ecology and biogeography (3).

The longest single chapter discusses the dynamics of grasshopper and locust outbreaks and plagues. Only in this chapter and an earlier section on swarm migrations is the information arranged by species; otherwise, it is organised by topics and truly comprehensive in scope. The book will thus be useful to many people who do not see themselves as 'acridologists' but wish to draw on the large store of information available from the research on these insects. They will not find all they want on any one topic within these 600 pages, 270 text-figures, 95 tables and 24 doublecolumn pages of index, but they will get the gist of it along with a guide to the rest supported by 1,700 references.

Uvarov's colleagues Z. Waloff, R. F. Chapman and N. D. Jago, who edited the text after his death, have added supplementary material to his drafts but have not attempted to write the planned chapters he had not yet drafted, on economic aspects and the principles of control. Instead, they have rounded the book off with what amounts to a testament, a late review paper of Uvarov's on "Current and future problems of acridology", which sets forth his matured views on population dynamics, control and research.

The book may be fairly described as a monument to the author in more ways than one. The huge edifice of modern acridology was built on his inspiration and drive. The book is also very much the man, in its detailed attention to the facts, and to gaps in them, in its exceptional biological span, its scepticism, criticism and proposals for research, and in its sense of continuity between science and practice that Uvarov always displayed, not least in the unconventional naming of his research organisation, the "AntiLocust Research Centre". As a more important illustration of that same point, the book incidentally goes some

way toward rehabilitating Uvarov's original discovery of phase transformation in locusts as the basis for a strategy of concentrating control operations on 'outbreak areas' where the swarming phase is produced from non-swarming precursors. Both ideas came under a cloud of criticism in the $1950 \mathrm{~s}$ and $1960 \mathrm{~s}$, not least because it turned out that the most notorious species, the Desert Locust, was highly mobile in both phases and did not have just a few, permanent, outbreak areas like the others. By the time this volume was written, however, enough new information had accmulated to show that even in this species phase change or "gregarisation" is crucial in plague development and occurs in geographically identifiable areas, which are indeed larger and less fixed than the outbreak areas of other species but still far smaller than the

\section{Calculating electronic structure}

Semiempirical Methods of Electronic Structure Calculation. Part A (vol. 7) Techniques. Pp. 274. Part B (vol. 8): Applications. Pp 274. Edited by G. A. Segal. (Plenum: New York and London, 1977.) \$47.40 each part.

With so many books available on molecular orbital theory it is hard to imagine many gaps in the literature. Nonetheless, with calculations being run increasingly by non-professional theoreticians there has been a need for a consumer guide to the various alternative semiempirical methods. To some extent the two volumes edited by Segal provide this service.

Most of the variants of molecular orbital techniques are the subjects of monographs but here in the first of the companion volumes several methods are summarised, each in about thirty pages. The individual contributors are distinguished advocates of the methods they describe; in particular the chapters on the PCILO and $\mathrm{X} \alpha$ methods will be welcomed as providing more convenient summaries than those formerly available. One would wish, however, that for the price the coverage had been more comprehensive. Although neglect of differential overlap and the methods based on this approximation are the subject of one chapter, it would have been helpful to have a full chapter on the MINDO method even if the editor (as is clear from his preface) does not approve of this variant.

The tone of part $\mathbf{A}$ is serious and the theoretical basis for semi-empirical theories is discussed in the longest vast region subsequently over-run by the swarms.

Uvarov surely went too far in his reiterated hope that the outbreak areas would one day be deliberately altered ecologically for the sole purpose of preventing locusts from swarming, once and for all. Nevertheless, for the more pressing purposes of human settlement, the necessary ecological changes have already occurred in some regions such as North America, and they will doubtless occur in laterdeveloping countries in due course. If the expected result is an endemic grasshopper problem replacing the locust invasions, we are fore-armed with this book.

J. S. Kennedy

J. S. Kennedy is External staff member, Agricultural Research Council, and Professor of Animal Behaviour at the Imperial College of Science and Technology, University of London, UK.

chapter by Kar1 Freed. Many users of semi-empirical methods, on the other hand, only seek justification in the quality of predictions made by their calculations. Some of these applications are the subjects of the chapters in Pant B.

Again, some well known names contribute. The topics to which the calculations are applied include thermochemistry; excited states of organic molecules; photochemistry; inorganic complexes; spin resonance parameters; solid-state problems; and electron scattering. Any non-specialist with a problem in one of these aneas would be very much helped in choosing the most sensible approximation to select and given an honest indication of the quality of results he might expect.

In one respect the two volumes do not quite provide the complete consumer's guide. Many chemists are not controlled by the technique they use but by the molecules they are studying. They are interested in several properties of the same group of molecules, perhaps the vibration frequencies, the $p \mathrm{Ka}$, the conformation and the $n m r$ chemical shifts. A question one is often posed is, "Which method will answer these questions for me?" and at the same time "Just how much computer time is likely to be required?". A complete guide for the non-specialist would contain a set of 'benchmark' problems on model systems with the results from the various approximations compared and timed. Despite this omission the volumes will not rest unused on library shelves.

\section{Graham Richards}

Graham Richards is Lecturer in the Physical Chemistry Laboratory and a
Fellow of Brasenose College, Oxford, UK. 